\title{
Prevalence of gastrointestinal parasites of dogs and community awareness about zoonotic diseases in Chagni town, northwestern Ethiopia
}

\author{
Nigatu Kebede ${ }^{1^{*}}$ \\ ${ }^{1}$ Akillu Lemma Institute of Pathobiology (ALIPB), Addis Ababa University, P. O. Box 1176, Addis \\ Ababa, Ethiopia \\ *Address for the author: E-mail: nigatukebede@yahoo.com,nigatu.kebede@aau.edu.et \\ Tel.: +251112763091, Fax: +251112755296, P. O. Box: 150480
}

\begin{abstract}
This cross-sectional study was conducted to estimate the prevalence of gastrointestinal helminth species found in stray dogs and to assess the awareness of the community about dog parasitic zoonoses in Chagni town, northwest Ethiopia. Standard fecal and postmortem examination and questionnaire survey methods were used to collect data. A total of 202 fecal samples were collected and examined using the Kato-Katz methodology to indicate intestinal helminthes in dogs of the study area. Postmortem examination was done on 9 stray dogs to detect the presence of adult worms. Necropsy of the 9 stray dogs revealed that all of them (100\%) were positive for at least one intestinal helminth parasite. The following cestodes were identified: Echinococcus granulosus, Taenia pisiformis, T. hydatigena, T. ovis, Dipylidium caninum and Mesocestoides. Other intestinal worms in dogs were Toxocaracanis, Tirchurisvulpis and Ancylostoma caninum. Most helminths were recovered from the large intestine. Of the interviewed community members, $68.3 \%$ reported that tapeworms locally called "kosso" were zoonotic agents, followed by roundworms, locally called "wosefat". Majority of the respondents reported they feed their own dogs raw condemned offal's and human. The findings showed that there is significant infestation of intestinal helminthes among the dogs of the study area coupled with the high levels of illiteracy among community members about canine parasites and transmission. This shows that immediate action needs to be taken to decrease infection rates in dogs and to raise education levels of the community about zoonotic diseases.
\end{abstract}

Keywords: Chagni; Dog; Helminthes; Intestinal parasites; Prevalence; Zoonoses 


\section{Introduction}

Dogs are the most successful canids, adapted to human habitation worldwide (Tannen, 2004), live in close association with humans, providing them with companionship and security, among others (Paul et al., 2010). Although dogs bring many advantages to human life, including being guides for blind people, therapeutic agents, security guards, and hunters, they are associated with many potentially zoonotic pathogens including parasites (Chomel, 2014). Gastrointestinal parasites are among the main enteropathogens and the major cause of mortality in dogs. Canine zoonotic helminths pose a public health risk through various ways (Habluetzelet al., 2003; Rubel and Wisnivesky, 2005; Dubnáet al., 2007). Canine and human infection with zoonotic helminths can occur through ingestion of the infective eggs and ingestion or skin penetration of the infective larvae, contact with animal hair (Habluetzelet al., 2003; Dubnáet al., 2007), food and water contaminated with dog excreta or secretions, and/or consumption of dog meat (Cui and Wang, 2001).

Previous studies indicated that canine zoonotic parasites include Toxocara canis, Diphyllobothrium latum, Ancylostoma spp., Uncinaria stenocephala (Joffe et al., 2011), and Echinococcus granulosus (Abdi et al., 2013). Human infection with Toxocara spp. is typically asymptomatic, however, some individuals developed visceral larva migrans and ocular toxocariasis (MacPherson et al., 2000; Ahn et al., 2014). Ancylostoma spp. are agents of cutaneous larva migrans (MacPherson et al., 2000) and Ancylostoma caninum has also been associated with eosinophilic enteritis in humans (Croese et al., 1994; Walker et al., 1995).

Zoonotic canine gastrointestinal parasites were reported worldwide, $4.4 \%$ in Saskatchewan(Gaunt and Carr, 2011), 7.4\% in Kerman city, Iran (Mirazaei and Fooladi, 2012),43.3\% in Ibadan, Nigeria (Ayinmode et al., 2016),52.6\% in Ashanti, Ghana (Amissah-Reynolds et al., 2016), 62.6\% in Accra, Ghana (Johnson et al., 2015), 68.4\%in Nigeria (Ugbomoiko et al., 2008), 75.26 and 84.78\% in Bahir Dar, Ethiopia (Abere et al., 2013)and 86.8\% in Hawassa, Ethiopia(Paulos et al., 2012) were reported. The variation in prevalence reported could be due to differences in status of dog sampled, geographical location, and the diagnostic techniques used (Robertson et al., 2000; Oliveira-Sequeira et al., 2002). High prevalence and heavy infections with gastrointestinal parasites are more commonly reported in dogs in developing countries (Perera et $a l ., 2013)$. This is attributed to the fact that dogs in these regions are rarely 
treated for parasitic diseases and policies on pet ownership are usually lacking (Ugbomoiko et al., 2008) or poorly enforced, thereby providing fertile grounds for zoonotic transmission of parasites. It is therefore important to understand the epidemiology of helminth infections in dogs to improve animal health and prevent the spread of zoonotic pathogens to humans. This study was aimed to estimate the prevalence of GIT parasites of dogs and assess the awareness of the community about dog parasitic zoonoses in Chagni town, northwest Ethiopia.

\section{Materials and methods}

\section{Study Area}

The study was conducted in Chagni (formerly called "Kedamawi Haile Selassie Ber") town in northwestern Ethiopia. Located in the Awi Zone of the Amhara National Regional State, this town has a longitude and latitude of $10^{\circ} 57^{\prime} \mathrm{N} 36^{\circ} 30^{\prime} \mathrm{E}$ and an elevation of 1583 meters above sea level. It is the administrative center of Guangua district (woreda) (Fig 1.). Based on the figures from the Central Statistical Agency 2005, Chagni has an estimated total population of 30,938, of whom 16,035 are men and 14,903 are women (CSA, 2005).

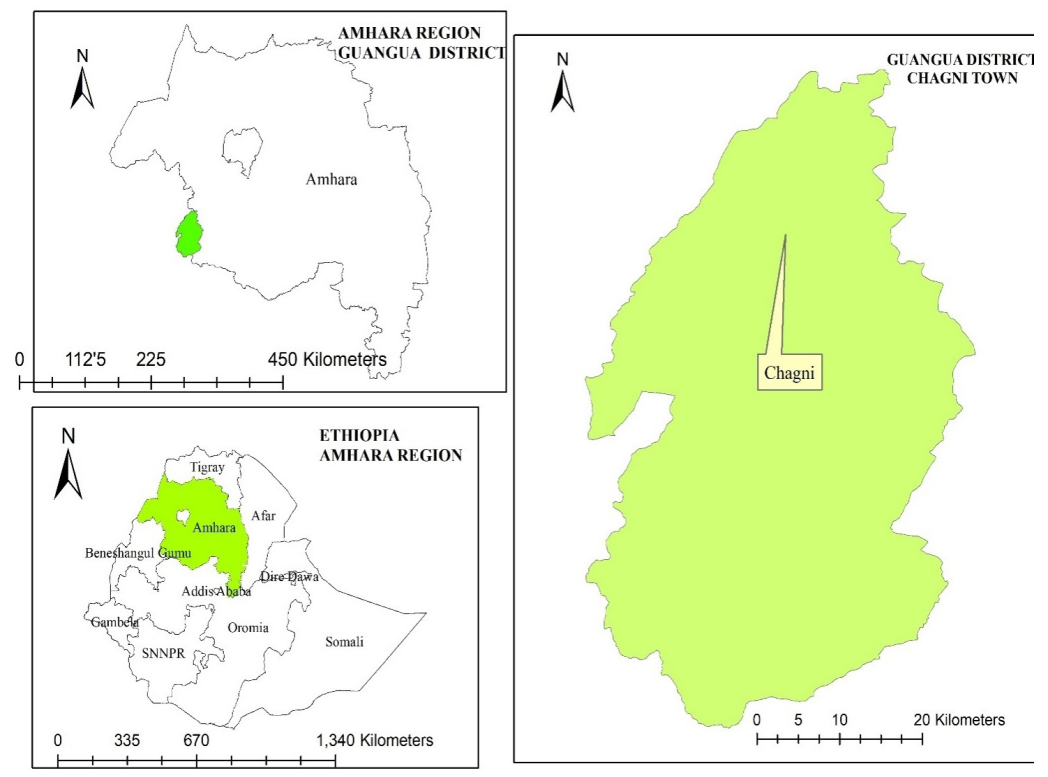

Figure 1: Map of the study area 


\section{Study animals and study design}

The study was conducted on stray dogs at chagni town using cross-sectional study design. Sample size was determined based on studies conducted previously (Amissah-Reynolds et al., 2016; Idika et al., 2017; Kiflu et al., 2016; Israel, 1992). Fecal sample collection and questionnaire were the methods used.

\section{Fecal sampling}

Fecal samples were collected from 202 stray dogs. In order to avoid repeat sampling of the same dog, sample collection was done in the morning in the places where dogs overnight and in different places at the same time as well as photo of each dog was taken using mobile phones. Furthermore, a number of individuals (trained animal heath technicians were involved to collect samples). Information was obtained on the approximate age, sex, and mode of life of each dog. Fecal samples were placed in clean $30 \mathrm{ml}$ bottles. About $10 \mathrm{~g}$ of feces from each dog were mixed thoroughly with $10 \%$ aqueous formaldehyde for preservation. Samples were examined for parasite eggs in the laboratory by means of the modified Kato-Katz procedure (Hendrix, 2003). Each parasite egg was identified using established structural and morphometric criteria (Soulsby, 1982).

\section{Postmortem examination}

This was conducted on 9 stray dogs euthanized by the municipal in Chagni. An abdominal cut was made in each animal and the intestine was tied from the pyloric and anal ends and collected in a bag. Bags were stored in an icebox and carried to the laboratory within 3 hours. The carcasses were burned in the field to ensure that there was no contamination of the environment. In the laboratory, each intestine was divided into four pieces of equal length. Each piece was cut longitudinally and soaked in $0.15 \mathrm{M}$ phosphate buffer saline (PBS, pH 7.2) for $5 \mathrm{~min}$. The mucosal lining was gently scraped with a spatula into clean glass dishes and the collected intestinal contents were left to settle in $1000 \mathrm{ml}$ conical Nalgene graduates (Nalge, Rochester, USA). Following several washes with PBS, aliquots were examined under a dissecting microscope. The preparation, staining and mounting of helminths were carried out as described by Meyer and Olsen (1980). Identification of intestinal helminths was based on keys and descriptions by Khalil et al. (1994). Identification of various Taenia species was based on stained specimens and comparison of scoleces and 
various types of proglottids as well as on morphometric measurements of small and large hooks of armed rostella (Soulsby, 1982).

\section{Questionnaire survey}

A total of 82 questionnaires were administered to household members of the community in Chagni town. A structured questionnaire was prepared in local language and a pilot test to validate the questionnaire was performed. The questionnaire was designed to gather information on dog ownership, feeding of dogs, treatment for dogs, the extent of awareness on dog parasites, control measures taken, the occupation of the dog's owner and other related factors. The participants were selected based on simple random sampling from the lists of kebeles in the town.

\section{Statistical analysis}

Statistical tests were performed using SPSS 20.0 (SPSS Inc., Chicago, Illinois, USA). The chi-square $\left(\mathrm{X}^{2}\right)$ test was used to assess difference in frequency of the helminthes between the sex and age groups. In all cases, $95 \%$ confidence intervals and $\mathrm{P}<0.05$, were set for significance.

\section{Results}

\section{Prevalence and species of gastrointestinal parasites in stray dogs}

The overall infestation of dogs with gastrointestinal parasites was $94.6 \%$ and $100 \%$ based on fecal examination and postmortem examination, respectively. Gastrointestinal helminth parasites of dogs identified based on fecal examination were: Taenia spp, Ancylostoma spp., Tirchuris vulpis, Toxocara canis, Dipylidium caninum, Strongyloides stercoralis and protozoa spp(Table 1). Infection with only one species of parasite was more common (35.6\%) than infection with two $(28.7 \%)$, three $(20.3 \%)$ or four $(9.9 \%)$ species. Overall frequency of infection with GI helminthes in dogs and frequency in different sex and age groups obtained by fecal examination was described in Table 2. Statistically significant variation was seen between age groups $(\mathrm{P}<0.05)$. 
Table 1: Intestinal parasites diagnosed in the faeces of dogs and their respective prevalence in Chagni, northwest Ethiopia

\begin{tabular}{lc}
\hline Parasite & No. (\%) Positive \\
\hline Taenia spp & $191(94.6)$ \\
Ancylostoma spp & $187(92.6)$ \\
Tirchuris vulpis & $178(88.1)$ \\
Toxocara canis & $177(88.0)$ \\
Dipylidium caninum & $124(61.4)$ \\
Strongyloidesstercoralis & $122(60.1)$ \\
Protozoa spp & $113(55.9)$ \\
\hline
\end{tabular}

Out of 9 male adult dogs examined at necropsy, all of them (100\%) harbored one or more GI helminthes. Of these, $77.8 \%$ were infected with two or more GI helminthes. Based on postmortem examination dog gastrointestinal helminthes identified were: Echinococcus granulosus, Taenia hydatigena, Taenia ovis, Ancylostoma caninum, Tirchuris vulpis, Toxocara canis and Dipylidium caninum. The study revealed that Taenia spp. was more prevalent followed by nematodes (Table 3). The dogs used for postmortem examination were adult (age greater than one year) males, no comparison was made between sex and age groups.

Table 2: Overall frequency of infection with GI helminthes in dogs and frequency in different sex and age groups obtained by coproscopical examination

\begin{tabular}{lccc}
\hline Sex of dogs & No. examined & No. (\%) infected & X2(P-value) \\
\hline Male & 121 & $117(96.7)$ & 0.113 \\
Female & 81 & $74(91.4)$ & $(\mathrm{P}>0.05)$ \\
Total & 202 & $191(94.6)$ & \\
Age of dogs (Months) & & & \\
$0-6$ & 24 & $17(70.8)$ & $(\mathrm{P}<0.05)$ \\
$7-11$ & 63 & $60(95.2)$ & \\
$\geq 12$ & 115 & $114(99.1)$ & \\
Total & 202 & $191(94.6)$ & \\
\hline
\end{tabular}


Table 3: Intestinal parasites of 9 adult male dogs identified based on postmortem examination in Chagni, northwest Ethiopia

\begin{tabular}{lc}
\hline Parasite & No. (\%) Positive \\
\hline Echinococcus granulosus & $8(88.9)$ \\
Taenia hydatigena & $6(66.7)$ \\
Taenia ovis & $4(44.4)$ \\
Ancylostoma caninum & $7(77.8)$ \\
Tirchuris vulpis & $7(77.8)$ \\
Toxocara canis & $8(88.9)$ \\
Dipylidium caninum & $6(66.7)$ \\
Mesocestodes & $9(100)$ \\
\hline
\end{tabular}

\section{Community awareness on zoonoses}

Of the community members, $68.3 \%$ reported that tapeworms (D. caninum, and hydatids (E. granulosus) locally called "kosso" were zoonotic agents, followed by roundworms (Toxocara, locally name "wosefat"). Of the owners who were aware of the potential for transmission of parasites from dogs to humans, none of them could provide correct information on the mode of transmission. Of the dog owners 50(61\%) had not treated their dogs using anthelmintics in their life time where as $39 \%$ treated their dogs using traditional preparations. Majority of the community (65.9\%) members reported feeding to dogs' raw condemned offals and human food and 61\% reported usual place for defecation of dogs is on the street (Table 4). 
Table 4: knowledge and attitudes of dog owners regarding potential zoonotic disease in the traditional communities of Chagni, northwestern Ethiopia

\begin{tabular}{|c|c|}
\hline Variables & No $(\%)$ \\
\hline \multicolumn{2}{|l|}{ Dog ownership } \\
\hline One dog & $50(61)$ \\
\hline Two or more dogs & $32(39)$ \\
\hline \multicolumn{2}{|l|}{ Occupation } \\
\hline Civil servant & $20(24.4)$ \\
\hline Marchant & $62(75.6)$ \\
\hline \multicolumn{2}{|l|}{ Reasons for keeping dog } \\
\hline Hunting & 0 \\
\hline Look after livestock & $41(51.2)$ \\
\hline No specific reason & $20(24.4)$ \\
\hline Look after the house at night & $20(24.4)$ \\
\hline \multicolumn{2}{|l|}{ Housing of dogs } \\
\hline Confined to dog house on compound & $32(39)$ \\
\hline Share the same house with the owners and livestock & $50(61)$ \\
\hline \multicolumn{2}{|l|}{ Feeding of dogs } \\
\hline Condemned offals & $28(34.1)$ \\
\hline Condemned offals and human food & $54(65.9)$ \\
\hline \multicolumn{2}{|l|}{ Usual place of defecation of dogs } \\
\hline Within the house premises & $32(39)$ \\
\hline On the street & $50(61)$ \\
\hline \multicolumn{2}{|l|}{ Do children play with dogs } \\
\hline Yes & $74(90.2)$ \\
\hline No & $8(9.8)$ \\
\hline \multicolumn{2}{|c|}{ Community awareness of diseases transmitted by dogs } \\
\hline Serious & 18(21.9) \\
\hline Not serious & $33(40.2)$ \\
\hline Do not cause any disease & $31(37.9)$ \\
\hline \multicolumn{2}{|l|}{ What are the main parasitic diseases of dogs } \\
\hline Taenia species (“Kosso” locally) & $56(68.3)$ \\
\hline Toxocaracanis ("wosefat") & 26(31.7) \\
\hline \multicolumn{2}{|l|}{ Treatment for dogs } \\
\hline Not at all & $50(61)$ \\
\hline Use traditional preparations & $32(39)$ \\
\hline
\end{tabular}




\section{Discussion}

The present study provides quantitative estimates of parasites in dogs in Chagni town, northwest Ethiopia. The results showed that gastrointestinal helminth species were abundant, and that prevalence of infection was very high whereas the awareness of the community about zoonotic diseases transmitted by pets was insufficient.

The parasites reported in this study have been previously documented in dogs throughout the world (Senliket al., 2006), with a pronounced difference in prevalence and density between regions. This discrepancy in the overall frequency rates reported in various countries could be attributed to the difference in health care and animal management practices followed in different countries.In our study gastrointestinal helminth infestation of dogs was found to be $94.6 \%$ and $100 \%$ based onfecal examination and postmortem examinations, respectively. There was no significant difference in the results obtained between the two techniques. The slight difference observed could be due to the fact that fecal examinations may not detect the immature parasites, which are unable to lay eggs. However, the overall frequency rate thus obtained on fecal examination is in agreement with previous works inTurkey (Senlik et al., 2006), Netherlands (Nobel et al., 2004), and in Greece (Haralabidis et al., 1988) but a lower frequency rate was recorded in Santa Catarina (Blazius et $a l .$, 2005) and in Nigeria (Ugochukwu and Ejimadu, 1985).

The difference in the frequency of the nematode infections between countries is possibly due to the differences in climatic factors required for the biology of the parasites, veterinary facilities and public awareness to take care of the dogs. During the survey it was noted that large number of dogs scavenge at abattoirs and at butcher shops and those kept indoors are also frequently fed uncooked offal that are not in good hygienic condition. It is also common to find animal cadaver thrown into street where dogs communally feed on, which could be a suitable media for transmission of the parasites.

This potential for human zoonotic disease has rarely been addressed in control programs in Ethiopia and other low-income countries (Merga and Sibhat, 2015). Considering the high prevalence of gastrointestinal helminth infections found in dogs, and the close bonds in which dogs live together with people, the risk of transmission of these parasites to humans seems to be obvious. For 
example, Toxocara infection in humans may cause visceral larva migrans, in severe cases leading to blindness (Taylor, 2001), and dog hookworm infections put humans at risk for cutaneous larva migrans which is endemic in many resource-poor communities (Heukelbach et al., 2005).

The prevalence reported in this study differs from those of Hailu et al., (2007) who recorded $51 \%$ based on fecal examination and nearly similar result on postmortem examination. The recorded high prevalence of gastrointestinal parasites of dogs in Chagni town may be due to poor awareness of the community. Our data shows that most dogs never or rarely received antiparasitic treatment during their puppy stage, and only few people were aware of the zoonotic potential of dog parasites.

The diagnostic technique of parasites done in this study, based on the morphological characteristics of ova under light microscope, has the disadvantage that it fails to distinguish $E$. granulosus from other Taenidae. Thus, E. granulosus, a major zoonotic parasite of livestock and dogs in Ethiopia (Kebede et al., 2009) may be highly prevalent as it is indicated in the postmortem examination. The fact that dogs enjoy unrestrained association with humans, scavenge for food in an environment contaminated with faecal material of potential intermediate hosts and feed on offal of slaughtered livestock in abattoirs (Jones et al., 2012) makes transmission of zoonotic parasitic diseases predictable in the setting studied.

In general, the trend in prevalence and species composition of parasites observed in this study may reflect the degree of environmental contamination in particular, $T$. canis, $A$. caninum and $D$. caninum are zoonotic parasites constituting public health problems in the study areas.

In conclusion, the study shows the presences of different nematode species in a single host as well as high frequency of these parasites in the study area which warrants serious attention due to pathogenic impact of the parasites. In addition, parasites of importance for human health were highly prevalent in Chagni area dogs and that intervention measures are necessary to reduce the risk of transmission of parasites from dogs to humans. Interventions should focus on health education provided to dog owners, strategic deworming of dogs using broad-spectrum anthelmintics and the establishment of a program based 
on zoonotic diseases, have paramount importance. Moreover, further epidemiological studies should be conducted seasonally in different regions of the country.

\section{Acknowledgements}

This work was financially supported by Addis Ababa University. W/ro Wolela Guade and Ato Mekuriaw Tessema are acknowledged for sample collection at Chagni.

\section{References}

Abdi, J., Asadolahi,K., Maleki, M. H. and Hafez, A. A., 2013. Prevalence of helminthes infection of stray dogs in Ilam province. J. Paramedical Sci., 4(2),47-50.

Abere, T., Bogale, B. and Melaku, A., 2013. Gastrointestinal helminth parasites of pet and stray dogs as a potential risk for human health in Bahir Dar town, northwestern Ethiopia. Vet World 6(7),388-392.

Abo-Shehada, M. N., 1989. Prevalence of Toxocara ova in some schools and public grounds in northern and central Jordan. Ann. Trop. Med. Parasitol., 83, 73-75.

Ahn, S.J., Ryoo, N.K., Woo, S.J., 2014. Ocular toxocariasis: clinical features, diagnosis, treatment, and prevention. Asia Pac. Allergy 4(3), 134-41.

Amissah-Reynolds, P.K., Monney, I., Adowah, L.M., andAgyemang, S.O., 2016. Prevalence of Helminths in Dogs and Owners' Awareness of Zoonotic Diseases in Mampong, Ashanti, Ghana. J. Parasitol. Res., Article ID 1715924, 6 pages. dx.doi.org/10.1155/2016/1715924

Ayinmode, A.B., Obebe, O.O., and ,Olayemi, E. 2016. Prevalence of potentially zoonotic gastrointestinal parasites in canine faeces in Ibadan, Nigeria. Ghana Med. J., 50(4), 201-206.

Blazius, R.D., Emerick, S., Prophiro, J, S, Romao, P.R. and Silva, O.S., 2005. Occurrence of protozoa and helminths in fecal samples of stray dogs from Itapema City Santa Catarina. Rev. Soc. Bras. Med. Trop., 38(1), 73-74.

Chomel, B.B.,2014. Emerging and re-emerging zoonoses of dogs and cats. Animals (Basel)4(4), 434-445.

Croese, J., Loukas, A., Opdebeeck, J., Prociv, P., 1994. Occult enteric infection by Ancylostoma caninum: a previously unrecognized zoonosis. Gastroenterol.,106 (1), 3-12.

CSA (2005). Central Statistical Agency of Ethiopia. Annual report. 
Cui, J. and Wang, Z.Q., 2001. Outbreaks of human trichinellosis caused by consumption of dog meat in China. Parasite, 8(2 Suppl), S74-S77.

Dubná, S., Langrová. I., Jankovská, I., Vadlejch, J, Pekár, S., Nápravník, J, Fechtner, J.,2007.Contamination of soil with Toxocara eggs in urban (Prague) and rural areas in the Czech Republic. Vet. Parasitol., 144, 81-6.

Gaunt, M. C. and Carr, A. P., 2011. A survey of intestinal parasites in dogs from Saskatoon, Saskatchewan. Canadian Vet. J.,52(5), 497-500.

Habluetzel, A., Traldi. G., Ruggieri. S., Attili. A., Scuppa. P., Marchetti. R., Menghini, G., Esposito, F., 2003. An estimation of Toxocara canis prevalence in dogs, environmental egg contamination and risk of human infection in the Marche region of Italy. Vet Parasitol.,113, 243-252.

Hailu, Y., Ayele, T., Fikru, R. and Basu, A.K., 2007. Gastrointestinal nematodes in dogs from Debre Zeit, Ethiopia. Vet. Parasitol., 148, 144-148.

Haralabidis, S.T, Papazachariadou, M.G., Koutinas, A.F. and Rallis, T.S.,1988. A survey on the prevalence of gastrointestinal parasites of dogs in the area of Thessaloniki, Greece. J. Helminthol., 62(1), 45-49.

Hendrix, C.M., 2003. Laboratory Procedures for Veterinary Technicians. $4^{\text {th }}$ edition, Mosby, Inc., USA, pp364.

Heukelbach, J., Walton, S.F., Feldmeier, H., 2005. Ectoparasitic infestations. Curr. Infect. Dis. Rep., 7(5), 373-80.

Idika, I.K., Onuorah, E.C., Obi, C.F., Umeakuana, P.C., Nwosu, C.O., Onah, D.N., and Chiejina, S.N., 2017. Prevalence of gastrointestinal helminth infections of dog in Enugu State, South Eastern Nigeria. Parasite Epidemiol Control, 2(3): 97-104.

Israel G. D., 1992. Sampling the evidence of extension program impact. Program Evaluation and Organizational Development, IFAS, University of Florida. PEOD-5.

Joffe, D., Van Niekerk, D., Gagne, F., Gilleard, J., Kutz, S. and Lobingier, R., 2011.The prevalence of intestinal parasites in dogs and cats in Calgary, Alberta. Can. Vet. J., 52(12), 1323-1328.

Johnson, S. A. M., Gakuya, D. W., Mbuthia, P. G., Mande, J. D., and Maingi, N., 2015. Prevalence of gastrointestinal helminths and management practices for dogs in the Greater Accra region of Ghana. Heliyon, 1(1), Article ID e00023.

Jones, O., Kebede, N., Kassa, T.,Tilahun. G., Macias, C., 2012. Occurrence of bovine hydatidosis and evaluation of its risk to humans in traditional communities of Southern Region of Ethiopia. Ethiop. J. Health Dev., 26(1), 43-48. 
Kebede, N., Mitiku, A. and Tilahun, G., 2009. Hydatidosis of slaughtered animals in Bahir Dar Abattoir, Northwestern, Ethiopia. Trop. Anim. Hlth. Prod., 41, 43-50.

Khalil, L.F., Jones, A., Bray, R.A., 1994. Keys of the cestode parasites of vertebrates. CAB International, Wallingford, UK, pp 751.

Kiflu, B., Abdurahaman, M., Alemayehu, H., and Eguale, T., 2016. Investigation on public knowledge, attitude and practices related to pet management and zoonotic canine diseases in Addis Ababa, Ethiopia. Ethiop. Vet. J., 20 (1), 67-78.

MacPherson, C.N.L., Meslin, F.X., Wandeler, A.I., 2000. Dogs, zoonoses and public health. Oxon, New York: CABI Publishing; pp. 213-56.

Merga, T., and Sibhat, B., 2015. Prevalence of gastrointestinal helminth parasites of dogs and associated risk factors in Adama Town, Central Ethiopia. Ethiop. Vet. J., 19 (2), 91-103.

Meyer, M.C. and Olsen, O.W., 1980. Essentials of parasitology. $5^{\text {th }}$ edition, Brown, Dubu-due, Iowa, USA, pp 298.

Mirazaei, M., andFooladi,M., 2012. The prevalence of intestinal helminths in owned dogs in Kerman city, Iran. Asian Pacific J. Trop. Med., 13(1), 735-737.

Nobel, W.E., Robben, S.R., Dopfer, D., Hendrix, W.M., Boersema, J.H., Fransen, F. and Eysker, M., 2004. Infections with endoparasites in dogs in Dutch animal shelters. Tijdschr. Diergeneeskd., 129(2), 40-44.

Oliveira-Sequeira, T.C. Amarante, A.F. Ferrari, T.B. and Nunes. L.C., 2002. Prevalence of intestinal parasites in dogs from Sao Paulo State, Brazil. Vet. Parasitol., 103(12), 19-27.

Paul, M. King,L. and Carlin,E. P.,2010. Zoonoses of people and their pets: a US perspective on significant pet-associated parasitic diseases. Trends in Parasitol., 26(4), 153-154.

Paulos, D., Addis, M., Fromsa, A. and Mekibib, B., 2012. Prevalence of gastrointestinal helminthes among dogs and owners perception about zoonotic dog parasites in Hawassa Town, Ethiopia. J. Pub. Hlth. Epid., 4(8), 205-209.

Perera, P.K., R. P. V. J. Rajapakse, and Rajakaruna, R. S., 2013. Gastrointestinal parasites of dogs in Hantana area in the Kandy District. J. National Sci. Found. Sri Lanka, 41(2), 81-91.

Robertson, I.D., Irwin P.J., Lymbery, A.J., Thompson R.C.A., 2000. The role of companion animals in the emergence of parasitic disease. Int. J. Parasitol., 30(12-13), 1369-1377. 
Rubel, D., Wisnivesky, C., 2005. Magnitude and distribution of canine fecal contamination and helminth eggs in two areas of different urban structure, greater Buenos Aires, Argentina. Vet Parasitol., 133, 339-47.

Senlik, B., Cirak, V.Y. and Karabacak, A., 2006. Intestinal nematode infections in Turkish military dogs with special reference to Toxocaracanis. J. Helminthol., 80, 299-303.

Soulsby, E.J.L., 1982. Helminthes, arthropods and protozoa of domesticated animals. The English Language Book Society and Bailliere Tindall, London, UK, pp809.

Tannen, D. 2004. Talking the dog: framing pets as interactional resources in family discourse. Res. Lang. Soc. Interac., 37, 399- 420.

Taylor, M.R. 2001. The epidemiology of ocular toxocariasis. J. Helminthol., 75(2), 10918.

Ugbomoiko, U. S., Ariza, L. and Heukelbach, J., 2008. Parasites of importance for human health in Nigerian dogs: high prevalence and limited knowledge of pet owners. BMC. Vet. Res.,4, article 49.

Ugochukwu, E.I. and Ejimadu, K.N., 1985. Studies on the prevalence of gastro-intestinal helminths of dogs in Calabar, Nigeria. Int. J. Zoonoses, 12 (3), 214-218.

Walker, N.I., Croese. J., Clouston. A.D., Parry. M., Loukas. A., Prociv, P., 1995. Eosinophilic enteritis in northeastern Australia. Pathology, association with Ancylostoma caninum, and implications. Am. J. Surg. Pathol., 19, 328-37. 